\section{Case Reports in Dermatology}

\title{
CD10-Positive Cutaneous PEComa: An Extremely Rare Skin Tumour
}

\author{
Simon Ueberschaar Matthias Goebeler Hermann Kneitz \\ Department of Dermatology, Venereology and Allergology, University Hospital Würzburg, \\ Würzburg, Germany
}

\section{Keywords}

PEComa · Cutaneous PEComa · Skin · CD10 - Perivascular epitheloid cell tumour

\begin{abstract}
We here present the case of a 67-year-old woman with a history of a slowly progressive, polypous nodule on her left wrist. The lesion was excised, and the histological analysis revealed a clear cell tumour that was relatively sharply demarked from the surrounding tissue extending into the subcutaneous tissue. The tumour showed a characteristic trabecular pattern in which the tumour cells were arranged around numerous vessels. The neoplastic cells had a predominantly epithelioid shape, granular eosinophilic to clear cytoplasm and prominent centrally located nucleoli. The histological differential diagnosis included a metastatic clear-cell renal cell carcinoma and a primary cutaneous perivascular epithelioid cell tumour (PEComa). Immunohistochemically, the tumour cells revealed homogenous expression of HMB-45, MiTF and CD10, whereas MART-1 and S100 were negative. Antibodies against actin marked the trabecularly arranged vessels, and the neoplastic cells yielded a patchy positivity against actin and desmin. Additional immunohistochemical stains against pan-cytokeratin, CAIX, PAX-8 and EMA were negative. Based on the morphologic and immunophenotypic findings, the histological diagnosis of a CD10-positive cutaneous PEComa was made.




\section{Case Reports in Dermatology}

Case Rep Dermatol 2020;12:192-198

DOI: $10.1159 / 000510718$

( 2020 The Author(s). Published by S. Karger AG, Basel www.karger.com/cde

Ueberschaar et al.: CD10-Positive Cutaneous PEComa: An Extremely Rare Skin Tumour

\section{Introduction}

First described in 2003 [1], primary cutaneous perivascular epithelioid cell tumours are rare mesenchymal tumours, representing $8 \%$ of all perivascular epithelioid cell tumours (PEComa) [2]. The relationship between cutaneous and extracutaneous PEComas has been questioned [3]. Cutaneous and extracutaneous PEComas show a different molecular signature [4]. PEComas are defined by characteristic histological and immunohistochemical properties $[4,5]$. Their histogenesis is uncertain and there are no known cellular counterparts to the distinctive neoplastic cell $[6,7]$. The perivascular epithelioid cells (PEC) have an epithelioid shape, a clear to pale eosinophilic cytoplasm, a predominantly perivascular location, and are characterized by the co-expression of melanocytic markers (HMB-45, MART-1, MiTF) and smooth muscle actin/desmin. An important differential diagnosis to cutaneous PEComa is cutaneous metastasis of clear cell renal cell carcinoma; distinction of both, however, is often difficult [7] and misdiagnosis may result in a fatal pitfall. While immunohistochemical positivity for CD10 had been considered as a reliable marker for cutaneous metastases of clear cell renal cell carcinoma, in 2016 Fernandez-Flores et al. [7] reported 3 cases of cutaneous PEComa that were marked by positivity for CD10 as well. Stuart et al. [6] described another 5 cases of CD10positive cutaneous PEComas.

We here report an additional case of primary cutaneous PEComa that is presenting with immunohistochemical positivity for CD10.

\section{Case Report}

A 67-year-old female presented with a slowly progressive, skin-coloured, $1.0 \times 0.8 \mathrm{~cm}$, polypous nodule on her left wrist. The tumour was completely excised, fixed in $10 \%$ buffered formalin and embedded in paraffin. Paraffin sections of $5 \mu \mathrm{m}$ were stained with haematoxylineosin. Microscopic analysis revealed a clear cell tumour extending into the subcutaneous tissue, which was relatively sharply demarked from the surrounding tissue. The panoramic view revealed a tumour-free marginal zone between the neoplasm and the epidermis. The tumour contained numerous vessels that were surrounded by tumour cells arranged in a characteristic trabecular pattern. The neoplastic cells presented with a predominantly epithelioid shape, clear cytoplasm and prominent, usually centrally located nucleoli. Mitotic activity and necrosis were absent (Fig. 1). Immunohistochemically, the tumour cells showed homogenous expression of HMB-45, MiTF and CD10 (Fig. 2), whereas MART-1 and S100 were negative. Antibodies against actin marked the trabecularly arranged vessels, and the neoplastic cells yielded a patchy/focal positivity for actin and desmin. Additional immunohistochemical stains against Pan-Cytokeratin, CAIX, PAX-8 and EMA were negative.

Based on the morphologic and immunophenotypic findings, we diagnosed a CD10-positive cutaneous PEComa.

\section{Discussion}

PEComas are rare mesenchymal neoplasms of yet uncertain histogenesis. The distinctive neoplastic cell has no yet identified cellular counterpart and shows immunoreactivity for both melanocytic and smooth muscle markers. It was first described in 1996 when authors noted a pancreatic tumour with striking similarities with visceral tumours previously reported 


\section{Case Reports in Dermatology}

Case Rep Dermatol 2020;12:192-198

DOI: $10.1159 / 000510718$

(c) 2020 The Author(s). Published by S. Karger AG, Basel www.karger.com/cde

Ueberschaar et al.: CD10-Positive Cutaneous PEComa: An Extremely Rare Skin Tumour

under several terms such as "clear cell sugar tumour," "angioleiomyoma," and "lymphangioleiomyoma," respectively [5, 8, 9]. In 2003, Crowson et al. [1] described the first primary cutaneous PEComa.

Clinically, cutaneous PEComas present as ill-defined, solitary, painless, skin-coloured nodules or plaques, which usually arise on the extremities. Cutaneous PEComas may occur at any age but are most frequent in middle-aged adults; women are more commonly affected than men [5, 10-12].

Histologically, primary cutaneous PEComas are characterized by a typical perivascular and occasionally radial arrangement of epithelioid cells with pale eosinophilic to finely granular clear cytoplasm and small central nuclei. While they mostly present with a perivascular architecture [6, 7], variants have been reported without a direct relationship to blood vessels. The cellular composition of PEComas may vary substantially; besides purely epithelioid forms, mixed cell and even spindle cell variants may be found $[3,13]$.

Immunohistochemically, PEComas express both melanocytic (HMB-45, MiTF, MelanA/MART-1, tyrosinase) and smooth muscle (desmin, SMA, calponin) markers. HMB-45 is the most sensitive marker [14]. Immunophenotypic findings of primary cutaneous PEComa were summarized by Charli-Joseph et al. [4] in 2014. In their review, data from 11 published studies and case reports showed that cutaneous PEComas may express HMB-45 (94\%), MelanA/MART-1 (35\%), NKI/C3 (100\%), MiTF (100\%), SMA (42\%), MSA (17\%), desmin (30\%), calponin (15\%) and caldesmon (8\%). Prior studies reported expression of smooth muscle markers in 50\% (5/10) and 57\% (4/7) of the cases [2, 5]. Primary cutaneous PEComas are less likely to express smooth muscle markers when compared to their soft tissue or visceral counterparts. Cytokeratins and SOX-10 are not expressed by cutaneous PEComas. S100 expression is seen in only a subset of cutaneous PEComas, while systemic PEComas can express S100 in up to $33 \%$ of the cases $[4,5,10]$.

CD10 expression was observed in cutaneous PEComas [6, 7], raising the concern for potential confusion with metastatic renal cell carcinoma. CD10 expression has also been reported in other clear cell tumours of the skin. Although rare, a clear-cell variant of atypical fibroxanthoma (AFX) has been described to be CD10-positive in 100\% (6/6) of cases [15]. Not surprisingly, CD10 expression is also common in dermatofibroma, a benign analogue of atypical fibroxanthoma [16]. CD10 was further found to be expressed in 32 of 35 xanthomatous clear cell lesions (xanthoma, xanthelasma and xanthogranoloma) [17].

PEComas should obviously be distinguished from melanocytic lesions. The studies by Guanziroli et al. [18] and Oba et al. [19] reported an increased expression of CD10 in up to $75 \%$ of all examined primary melanomas of the skin. Cutaneous PEComas normally express CD10 and other melanocytic markers, but only very rarely S100 and SOX10, whereas most melanomas do. Moreover, a junctional melanocytic component should be searched for since it is evidenced as a crucial clue to a melanocytic tumour [18].

CD10 expression has also been demonstrated in visceral PEComas of the uterus [20, 21], while no expression was seen in PEComas of the retroperitoneum, ileum, laryngopharynx or the liver [7]. None of the cases showed chromosomal imbalances (aCGH analysis) or initiating mutations. DNA sequencing demonstrated wild-type alleles for BRAF, NRAS, KIT, GNAQ, and GNA11 [4].

Diagnosing primary cutaneous PEComas is challenging given their rarity and their potential similarity to a long list of other cutaneous tumours that can undergo clear cell change. Most importantly to name are metastases of renal cell carcinomas, which are rare as well [22, 23]. Others are clear cell dermatofibroma and clear-cell variants of atypical fibroxanthoma, clear-cell xanthoma, balloon-cell melanoma and balloon-cell nevus, paraganglioma-like 


\section{Case Reports in Dermatology}

dermal melanocytic tumours, sebaceous carcinoma [7], clear-cell sarcoma and dermal clear cell mesenchymal neoplasm [6].

Overall, the prognosis of cutaneous PEComas is favourable. Primary cutaneous PEComas are generally considered benign, although there have been two case reports describing malignant primary cutaneous PEComas $[11,12]$.

\section{Conclusion}

Recent publications and our case show that CD10 is not a suitable marker for reliable differentiation between primary cutaneous PEComa and metastasis of clear cell renal carcinoma, since cutaneous PEComas also frequently express CD10. For a precise diagnosis of PEComa, a comprehensive immunohistochemical analysis with a panel of multiple antibodies is required.

\section{Statement of Ethics}

The patient provided written informed consent to perform all necessary investigations. This case report was conducted ethically in accordance with the World Medical Association Declaration of Helsinki.

\section{Conflict of Interest Statement}

The authors have no conflicts of interest to declare.

\section{Funding Sources}

This publication was supported by the Open Access Publication Fund of the University of Würzburg, Germany.

\section{Author Contributions}

All named authors meet the International Committee of Medical Journal Editors (ICMJE) criteria for authorship of the manuscript, take responsibility for the integrity of the work as a whole, and gave final approval to the version to be published.

\section{References}

1 Crowson AN, Taylor JR, Magro CM. Cutaneous clear cell myomelanocytic tumor perivascular epitheloid cell tumor: first reported case. Mod Pathol. 2003;16:400.

2 Mentzel T, Reisshauer S, Rütten A, Hantschke M, Soares de Almeida LM, Kutzner H. Cutaneous clear cell myomelanocytic tumour: a new member of the growing family of perivascular epithelioid cell tumours (PEComas). Clinicopathological and immunohistochemical analysis of seven cases. Histopathology. 2005 May;46(5):498-504.

3 Walsh SN, Sangüeza OP. PEComas: a review with emphasis on cutaneous lesions. Semin Diagn Pathol. 2009 Aug;26(3):123-30. 


\section{Case Reports in Dermatology}

\begin{tabular}{l|l}
\hline DOI: $10.1159 / 000510718$ & $\begin{array}{l}\text { (c) } 2020 \text { The Author(s). Published by S. Karger AG, Basel } \\
\text { www.karger.com/cde }\end{array}$
\end{tabular}

Ueberschaar et al.: CD10-Positive Cutaneous PEComa: An Extremely Rare Skin Tumour

4 Charli-Joseph Y, Saggini A, Vemula S, Weier J, Mirza S, LeBoit PE. Primary cutaneous perivascular epithelioid cell tumor: a clinicopathological and molecular reappraisal. J Am Acad Dermatol. 2014 Dec;71(6):1127-36.

5 Liegl B, Hornick JL, Fletcher CD. Primary cutaneous PEComa: distinctive clear cell lesions of skin. Am J Surg Pathol. 2008 Apr;32(4):608-14.

6 Stuart LN, Tipton RG, DeWall MR, Parker DC, Stelton CD, Morrison AO, et al. Primary cutaneous perivascular epithelioid cell tumor (PEComa): five new cases and review of the literature. J Cutan Pathol. 2017 Aug;44(8):713-21.

7 Fernandez-Flores A, Nguyen CM, Cassarino DS. Cutaneous PEComas express CD10: implications for the classification of PEComas and the differential diagnosis with metastatic renal cell carcinoma. Am J Dermatopathol. 2016 Sep;38(9):645-52.

8 Argani P, Aulmann S, Illei PB, Netto GJ, Ro J, Cho HY, et al. A distinctive subset of PEComas harbors TFE3 gene fusions. Am J Surg Pathol. 2010 Oct;34(10):1395-406.

9 Folpe AL, Mentzel T, Lehr HA, Fisher C, Balzer BL, Weiss SW. Perivascular epithelioid cell neoplasms of soft tissue and gynecologic origin: a clinicopathologic study of 26 cases and review of the literature. Am J Surg Pathol. 2005 Dec;29(12):1558-75.

10 Llamas-Velasco M, Mentzel T, Requena L, Palmedo G, Kasten R, Kutzner H. Cutaneous PEComa does not harbour TFE3 gene fusions: immunohistochemical and molecular study of 17 cases. Histopathology. 2013 Jul;63(1):122-9.

11 Calder KB, Schlauder S, Morgan MB. Malignant perivascular epithelioid cell tumor ('PEComa'): a case report and literature review of cutaneous/subcutaneous presentations. J Cutan Pathol. 2008 May;35(5):499-503.

12 Greveling K, Winnepenninckx VJ, Nagtzaam IF, Lacko M, Tuinder SM, de Jong JM, et al. Malignant perivascular epithelioid cell tumor: a case report of a cutaneous tumor on the cheek of a male patient. J Am Acad Dermatol. 2013 Nov;69(5):e262-4.

13 Kneitz H, Mentzel T, Wobser M, Goebeler M. Cutaneous PEComa of the right lower leg. J Dtsch Dermatol Ges. 2015 Aug;13(8):815-7.

14 Chaplin A, Conrad DM, Tatlidil C, Jollimore J, Walsh N, Covert A, et al. Primary cutaneous PEComa. Am J Dermatopathol. 2010 May;32(3):310-2.

15 Tardío JC, Pinedo F, Aramburu JA, Martínez-González MÁ, Arias D, Khedaoui R, et al. Clear Cell Atypical Fibroxanthoma: clinicopathological study of 6 cases and review of the literature with special emphasis on the differential diagnosis. Am J Dermatopathol. 2016 Aug;38(8):586-92.

16 de Feraudy S, Mar N, McCalmont TH. Evaluation of CD10 and procollagen 1 expression in atypical fibroxanthoma and dermatofibroma. Am J Surg Pathol. 2008 Aug;32(8):1111-22.

17 Perna AG, Smith MJ, Krishnan B, Reed JA. CD10 is expressed in cutaneous clear cell lesions of different histogenesis. J Cutan Pathol. 2005 May;32(5):348-51.

18 Guanziroli E, Venegoni L, Fanoni D, Cavicchini S, Coggi A, Ferrero S, et al. Immunohistochemical expression and prognostic role of CD10, CD271 and Nestin in primary and recurrent cutaneous melanoma. G Ital Dermatol Venereol. 2018 Sep. DOI: 10.23736/S0392-0488.18.06145-X.

19 Oba J, Nakahara T, Hayashida S, Kido M, Xie L, Takahara M, et al. Expression of CD10 predicts tumor progression and unfavorable prognosis in malignant melanoma. J Am Acad Dermatol. 2011 Dec;65(6):115260.

20 Fadare 0, Parkash V, Yilmaz Y, Mariappan MR, Ma L, Hileeto D, et al. Perivascular epithelioid cell tumor (PEComa) of the uterine cervix associated with intraabdominal "PEComatosis": A clinicopathological study with comparative genomic hybridization analysis. World J Surg Oncol. 2004 Oct;2(1):35.

21 Fang CL, Lin YH, Chen WY. Microscopic endometrial perivascular epithelioid cell nodules: a case report with the earliest presentation of a uterine perivascular epithelioid cell tumor. Diagn Pathol. 2012 Sep;7(1):117.

22 Fernandez-Flores A. Cutaneous metastases: a study of 78 biopsies from 69 patients. Am J Dermatopathol. 2010 May;32(3):222-39.

23 Terada T. Cutaneous metastasis of renal cell carcinoma: a report of two cases. Int J Clin Exp Pathol. 2012;5(2):175-8. 


\section{Case Reports in Dermatology}
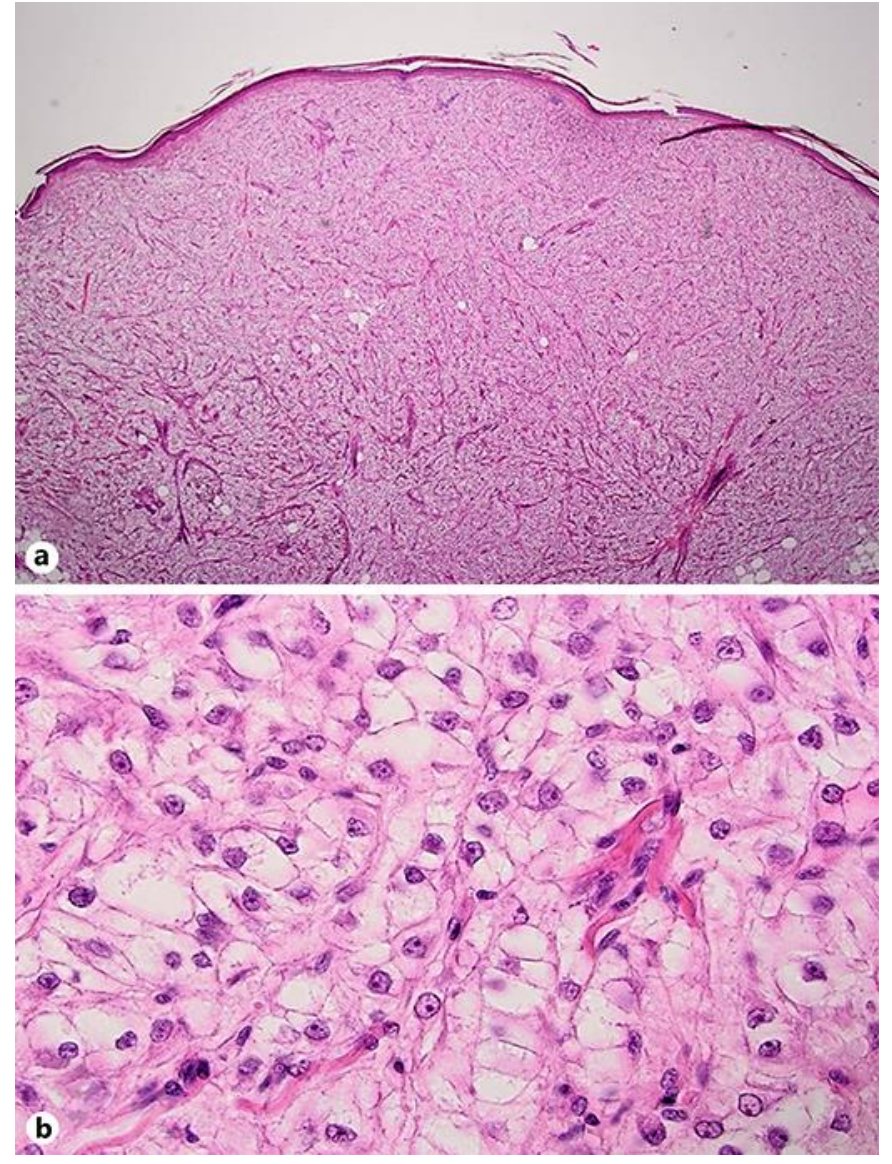

Fig. 1. a Dermal clear cell tumour with a marginal zone separating it from the overlying epidermis. Haematoxylin-eosin, original magnification $\times 12.5$. $\mathbf{b}$ Capillary vessels surrounded by nests of clear epithelioid cells. Haematoxylin-eosin, original magnification $\times 400$. 


\section{Case Reports in Dermatology}

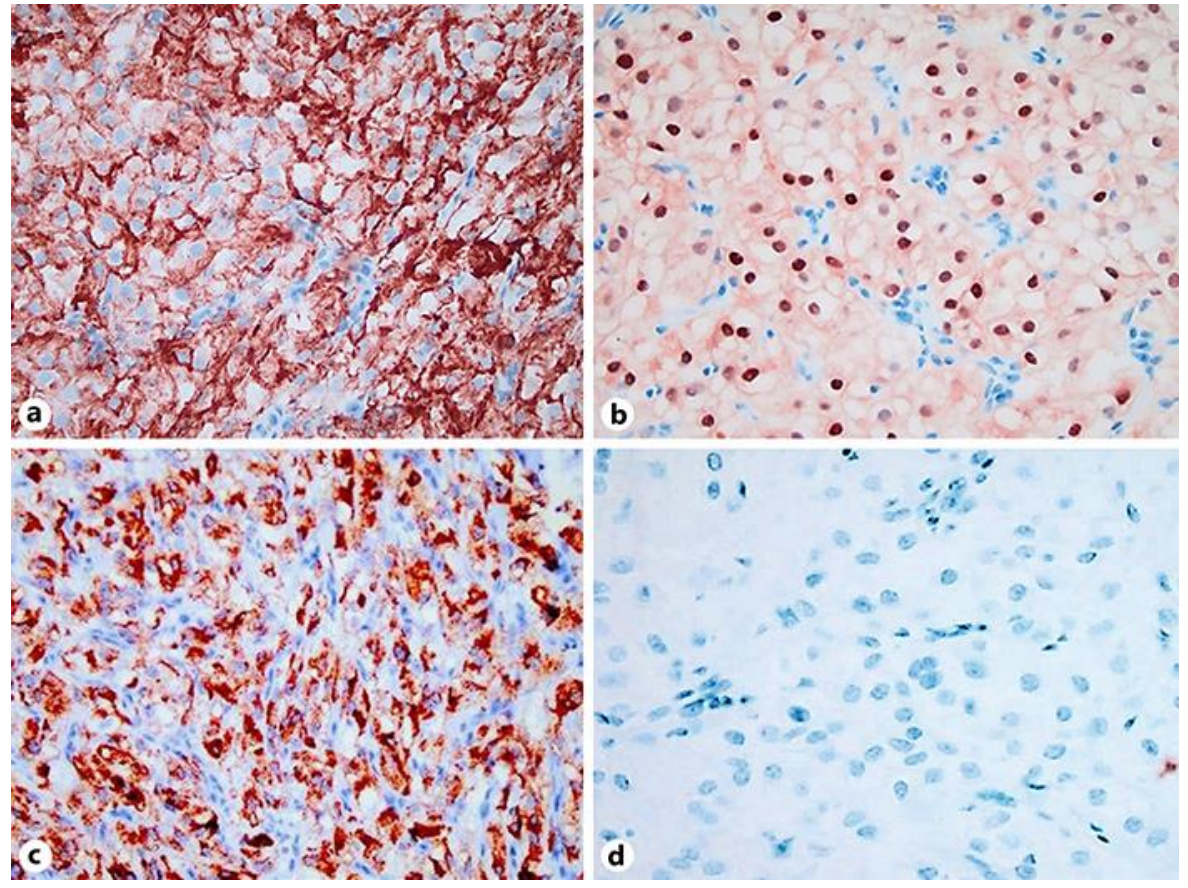

Fig. 2. PEComa with immunohistochemical positivity for CD10 (a), MiTF (b), and HMB-45 (c) and negativity for Pan-Cytokeratin (d). Original magnification (a-d) $\times 400$. 